Published in "Biological Conservation 241(): 108326, 2020"

which should be cited to refer to this work.

\title{
Apex predators decline after an influx of pastoralists in former Central African Republic hunting zones
}

\author{
Thierry Aebischer ${ }^{\mathrm{a}, \mathrm{b}}$, Tidjani Ibrahim ${ }^{\mathrm{c}, \mathrm{d}}$, Raffael Hickisch ${ }^{\mathrm{e}}$, Roman D Furrer ${ }^{\mathrm{f}}$, \\ Christoph Leuenberger ${ }^{g}$, Daniel Wegmann ${ }^{\mathrm{a}, \mathrm{b}, *}$ \\ ${ }^{a}$ University of Fribourg, Department of Biology, Chemin du Musée 10, CH-1700, Fribourg, Switzerland \\ ${ }^{\mathrm{b}}$ Swiss Institute of Bioinformatics, $\mathrm{CH}-1700$ Fribourg, Switzerland \\ ${ }^{\mathrm{c}}$ Université de Bangui, Laboratoire d'Economie Rurale et de Sécurité Alimentaire (LERSA), Avenue des Martyrs, BP-1450, Bangui, Central African Republic \\ ${ }^{\mathrm{d}}$ Université de Lille Centre Lillois d'Etudes et de Recherches Economique et Sociologiques (CLERSE), Cité Scientifique, Villeneuve d'Ascq, FR-59655, Lille, France \\ ${ }^{\mathrm{e}}$ University of Oxford, Department of Zoology, Wildlife Conservation Research Unit (WildCRU), The Recanati-Kaplan Centre, TubneyHouse, Tubney, OX13 5QL, United \\ Kingdom \\ ${ }^{\mathrm{f}}$ Kollegium St. Fidelis, Mittelschule in Nidwalden, Mürgstrasse 21, CH-6371 Stans, Switzerland \\ ${ }^{g}$ University of Fribourg, Department of Informatics, Bd de Pérolles 90, CH-1700, Fribourg, Switzerland
}

A R T I C L E IN F O

\section{Keywords:}

Lion

Leopard

Wild dog

Call-up survey

Track-count

Camera-trap

\begin{abstract}
A B S T R A C T
Pastoralism is spreading in Central Africa, where many protected areas are under consideration to be opened for grazing, in particular hunting zones. Here we document the loss of biodiversity followed by an influx of transhumant pastoralism into previously uninhabited and virtually pristine habitat in the Central African Republic. Our track count and camera trap surveys of 2012, 2016 and 2017 evidence a reduction of apex predators, particularly Northern lions (Panthera leo leo) and African wild dogs (Lycaon pictus), of which about 95\% and $80 \%$ were lost, respectively. While some large herbivores such as Western African buffalo (Syncerus caffer nanus) or Eastern giant eland (Tragelaphus derbianus gigas) were also strongly reduced, most herbivores remain at significant densities. Apex predator populations did thus not crash due to a lack of prey, but rather due to targeted killing by herders and accompanying merchants, as interviews confirmed. Our call-up survey suggests that lions were attracted by livestock outside of actively protected areas, were they got poisoned or shot. These findings exemplify the potential negative effects of pastoralism on wildlife even in large areas with intact habitat. We thus caution against the transformation of protected areas or hunting zones into pasture land, unless such a land-use change can be carefully managed and strictly controlled.
\end{abstract}

\section{Introduction}

Apex predators are currently threatened worldwide, particularly in West- and Central Africa, where many populations recently crashed (e.g. Giordano et al., 2017; Brugière et al., 2015). Due to their position at the top of trophic interactions, apex predators have generally low densities and are sensitive to changes in the community (Ripple et al., 2014). They further pose a threat for humans and livestock, and are therefore in direct conflict with pastoralists and farmers (Lamarque et al., 2009). While apex predators are thus particularly vulnerable to land-use change, their conservation is crucial to preserve complex ecosystems. Indeed, the loss of apex predators may alter the entire community, which can provoke habitat turnover, alterations to biogeochemical cycles, and a general loss of biodiversity (Ripple et al.,
2014).

Apex predators are most effectively protected in small fenced reserves (Packer et al., 2013; Bauer et al., 2015). But due to their low densities and extended home ranges, isolated populations may overexploit their prey (Hayward et al., 2007) and are at risk of inbreeding, stochastic catastrophic events and edge effects (Woodroffe, 1998), unless managed carefully and across reserves (Davies-Mosert et al., 2015). Unfortunately, only few large wilderness areas remain in Africa that could support sustainable apex predator populations in the long term.

The eastern Central African Republic (CAR) is one such potential area with $100,000 \mathrm{~km}^{2}$ of virtually pristine habitat devoid of permanent human settlements and formally protected as national parks, nature reserves and hunting zones. Despite this protection, most wildlife populations were decimated over the past 40 years by meat and ivory

\footnotetext{
* Corresponding author at: University of Fribourg, Department of Biology, Chemin du Musée 10, CH-1700, Fribourg, Switzerland.

E-mail addresses: thierry.aebischer@unifr.ch (T. Aebischer), ibratid@gmail.com (T. Ibrahim), raffaelhickisch@gmail.com (R. Hickisch), roman1.furrer@gmail.com (R.D. Furrer), christoph.leuenberger@unifr.ch (C. Leuenberger), daniel.wegmann@unifr.ch (D. Wegmann).
} 
poaching (Bouché et al., 2012). Nonetheless, the region is considered a stronghold for lions (Mésochina et al., 2010; Riggio et al., 2013), leopards (Jacobson et al., 2016), spotted hyenas (Bohm and Höner, 2015), and African wild dogs (Hickisch and Aebischer, 2013). The status of cheetahs is unknown, but they were reported from the northern CAR (Brugière et al., 2015).

The eastern CAR wilderness has recently come under threat of encroachment by nomadic pastoralists and their livestock. Pastoralists from the arid Sahel have gradually extended their range to the humid equatorial savanna over the past decades (Zecchini and Mattiello, 2016). But this process has recently intensified, driven by overgrazing, human population growth, extended droughts, regional conflicts, and aided by the availability of drugs against Trypanosomiasis (Malith and Ahmed, 2017). In light of this increased pressure, protected areas in West and Central Africa are currently under pressure to be open for livestock grazing (Niamir-Fuller et al., 2012; Macdonald et al., 2017).

For grasslands, pastoralism has often been suggested as a sustainable form of land-use that can preserve or even elevate biodiversity (McGahey et al., 2014). Compared to other forms of agriculture, extensive pastoralism does not necessarily alter the natural landscape and may thus coexist with the native vegetation and wildlife (Fynn et al., 2016). In areas that have lost their natural herbivores, pastoralism further helps to keep the landscape open and hence to maintain biodiversity (Pykälä, 2000). However, pastoralism was recently linked to reduced activity of many mammals in Western Africa (Harris, 2019), and its impact on previously uninhabited regions is not well understood, particularly in the absence of strict conservation management.

Here we assessed the populations of apex predators and their main prey in the heart of the eastern CAR wilderness area at the onset (2012) and four to five years after an illegal influx of a transhumant pastoralist community. We documented the impact of this land-use change using camera trap, track count and call-up surveys in about $6,000 \mathrm{~km}^{2}$ that were formerly defined as hunting zones and are currently managed as part of the nature reserve Aire de Conservation de Chinko (ACC). Using a novel Bayesian method combining data of multiple surveys, we then quantified the impact of this land-use change on population densities of apex predators and their main prey. Finally, we conducted interviews with pastoralists entering the ACC to better understand the social dynamics of their recent expansion affecting many protected areas in the African savannah-belt.

\section{Material and methods}

\subsection{Study site}

The eastern Central African Republic (CAR) consists of approximately $100,000 \mathrm{~km}^{2}$ of continuous intact habitat, spanning the ecotone between the wet Congolian rainforest and the dry Sahelo-Sudanian savanna with annual precipitation between $1,740 \mathrm{~mm}$ and $710 \mathrm{~mm}$ (Fick et al., 2017, Fig. 1A,B). The Eastern CAR Wilderness is devoid of permanent human settlements, forestry or agriculture, and crossed by only few public roads in the extreme north. The entire region is formally protected as national parks, nature reserves and hunting zones, but hardly managed (Blom et al., 2004).

In 2014, the nature reserve Aire de Conservation de Chinko (ACC) was established by the government of the CAR to enable law enforcement in $19846 \mathrm{~km}^{2}$ of this wilderness (Fig. 1A,B). It currently encompasses the former hunting zones Bas-Chinko 48, Chinko 40, Mbari 39 and Vovodo-Chinko 41, but is under way to be enlarged and become an official Faunal Reserve or National Park. The ACC is managed by the African Parks Network, which enforces a strict reserve with no human disturbance in a constantly enlarged core zone of about 2300,6000 and $17000 \mathrm{~km}^{2}$ in 2016, 2017 and 2019, respectively. The rest of the ACC is managed as a buffer where poaching and livestock grazing cannot be prevented completely.

The managed area is hilly, between 500 and 855 MASL, and consists of intact Sudano-Guinean savanna with patches of Northeastern Congolian lowland rainforest along rivers, streams and gorges (Boulvert, 1985). Annual precipitation, mostly accumulating during the rainy season from May to October, varies from 1340 to $1740 \mathrm{~mm}$ on a northeast to southwest gradient (Fick et al., 2017). So far, our ongoing surveys have identified flagship species like the Eastern giant eland (Tragelaphus derbianus gigas) (Brandlová et al., 2018), both African elephants (Loxodonta cyclotis and L. africana), giant forest hog (Hylochoerus meinertzhageni), common hippopotamus (Hippopotamus amphibius), Eastern chimpanzee (Pan troglodytes schweinfuthii) (Aebischer et al., 2017) and 26 different carnivore species.

\subsection{Density surveys}

We conducted three surveys (Fig. 1C) in and around the core zone of the ACC: Survey A in 2012, during which pastoralism became omnipresent for the first time (Mésochina, 2009). Survey B in 2016 and 2017, which marked the beginning of active law-enforcement (African Parks Annual Reports 2016). Survey C in 2019, during which an enlarged core zone was kept virtually free of pastoralists. All surveys were conducted in the dry seasons using camera traps and / or track counts to assess the density of the four apex predators Northern lion (Panthera leo leo), leopard (Panthera pardus), spotted hyena (Crocuta crocuta) and African wild dog (Lycaon pictus), and their main mammalian prey. For comparison, we further used camera traps to record three felids from the Caracal-lineage, the serval (Leptailurus serval), the golden cat (Caracal aurata) and the caracal (C. caracal), but without distinguishing among them.

\subsubsection{Prey species surveyed}

While little is known about prey preferences of apex predators in the region, African apex predators generally feed on a wide range of medium $(10-180 \mathrm{~kg})$ to large $(180-550 \mathrm{~kg})$ species that occur at high density and afford the hunter minimal risks of injury (Hayward, 2006, 2006a, 2006b, 2006c; Hayward and Kerley, 2005). Correspondingly, the only study reporting prey preferences for the Central African Republic noted that while lions preferred Western African buffalo (Syncerus caffer nanus), they fed on a wide range of species mostly according to their density, as did leopards, cheetah, spotted hyenas and African wild dogs (Ruggiero, 1991). We thus surveyed all mammals matching the above size range (Table A1). Importantly, we also included several typical forest dwellers that were reasonably abundant in the open woodland savanna or on edaphic grassland and were thus likely prey for apex predators in the ACC, as was reported from other forest-savanna ecotones (Van Orsdol, 1984), local trophy hunters and suggested by our own observations.

\subsubsection{Track count surveys}

We conducted track count surveys of 500, 1,155 and $759 \mathrm{~km}$ during the dry seasons (March and April) of 2012 (Survey A), 2017 (Survey B) and 2019 (Survey C), respectively, on the existing roads and along major rivers and ponds (Fig. 1, A1). Individual segments were surveyed between one and five times over the season. Survey A was mainly done on foot because of a shortage of vehicles and fuel due to political instability. However, we were able to frequently use cars for Surveys B and C. In all years, the survey team lead by TA consisted of four observers: two focused on the road ahead, and one on either side of the road. When driving, we drove at $10 \mathrm{~km} / \mathrm{h}$ or less, and a brief comparison on $50 \mathrm{~km}$ showed no systematic differences between track counts on foot versus car (Text A1). We recorded and georeferenced all fresh tracks of apex predators and large herbivores ( $>180 \mathrm{~kg}$ ), and any signs of illegal human activity. While smaller mammals generally left too many tracks to be individually recognizable, we did record tracks of aardvarks and olive baboons (Papio anubis) as those might be confused with large ungulates or apex predators, respectively. Tracks were considered independent events if they were more than $500 \mathrm{~m}$ apart. The 

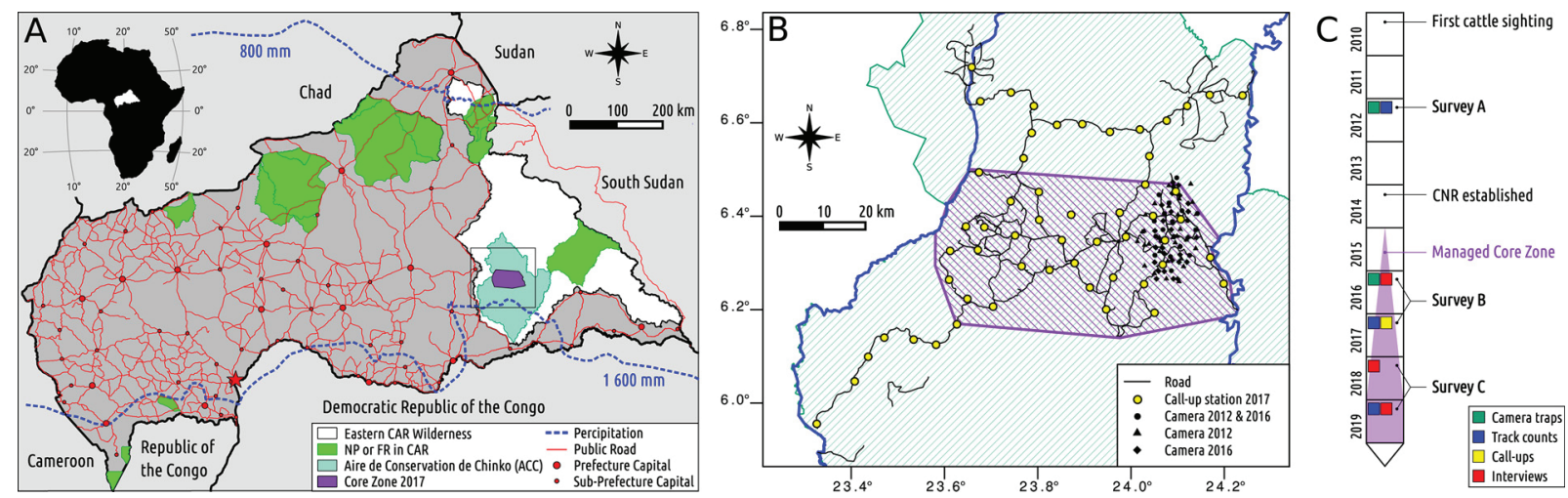

Fig. 1. A) Map of the Central African Republic showing the uninhabited wilderness that spans the wide ecotone between the wet Congolian rainforest in the south ( $>1600 \mathrm{~mm}$ of annual precipitation) and the dry Sahelo-Sudanian savanna in the north ( $<800 \mathrm{~mm}$ ). Indicated are all recognized national parks (NP) and faunal reserves (FR), including the Aire de Conservation de Chinko (ACC) with its core zone (status 2017). B) Study site (5.9-6.8 ${ }^{\circ} \mathrm{N}$ and $23.3-24.3^{\circ} \mathrm{E}$ ) with road network, camera trap and call-up locations (colors as in A). C) Timeline of the three surveys conducted here.

substrate, as determined every $500 \mathrm{~m}$, was variable with few stretches of dust or sand (11\%) but mostly of compact soil or gravel (75\%), often covered with leaves or grass (14\%). Despite this rather poor-quality substrate, tracks of common species such as olive baboons and aardvark were regularly observed, suggesting sufficient detectability.

\subsubsection{Direct sightings}

During Surveys A and B, we also recorded and georeferenced all direct sightings of mammals $>1 \mathrm{~kg}$. We used binoculars (Swarovski EL $12 \times 50^{\circ}$ ), digital cameras with high zoom (Canon Powershot HS50/ 60 ) or both to identify the species and the group size. We further measured the distance from the observer with a Leica 1600 rangemaster and recorded the angle to the transect. Since animals might react differently to observers walking or driving, we abstained from comparing counts between surveys.

\subsubsection{Camera trap surveys}

We utilized mostly Bushnell Trophy Cams 119436-119776 and few Reconyx HC500 HyperFire Semi-Covert IR models mounted on trees at about $50 \mathrm{~cm}$ above ground and at least three $\mathrm{m}$ from the focal point to capture both small (e.g. mice) and large animals (e.g. elephant). Camera traps were set to take three pictures when triggered. The interval between triggers was either 1-2 s, or three minutes if the focus was on an area or focal activity (e.g. salt lick). During the dry seasons (February to May) of 2012 (Survey A) and 2016 (Survey B), we ran 50 camera traps uniformly distributed within about $240 \mathrm{~km}^{2}$ inside the core zone of the ACC. Of these, 19 were mounted at the same location in both surveys. The total effort was 1430 camera trap days in both surveys. We manually annotated apex predators, prey species, livestock and humans on all pictures. To estimate changes in species densities, we compared the number of traps per survey that recorded a species at least once.

\subsubsection{Call-up survey}

In March and April 2017 (Survey B), we conducted call-up surveys for lions and spotted hyenas (Webster et al., 2010). To maximize the response of both males and females, and to prevent attracting only hungry individuals (Cozzi et al., 2013), we broadcasted mixed stimuli: i) prey distress calls of a buffalo calf and a hippopotamus, ii) competitor calls consisting a hyena giggling at a kill, and iii) social stimuli consisting of a lioness roaring and hyena making long-distance contact calls. These stimuli were broadcasted four times for $10 \mathrm{~min}$ with five minutes breaks using a Snow-Crow Pro 5 game call system and four high-performance conical speakers (FOXPRO INC) placed on the roof of a car at three meters above ground. The volume at one $\mathrm{m}$ from the speakers was tuned to $110 \mathrm{~dB}$, which lies within the natural pressure level of the two species (Webster et al., 2010).

We conducted call-ups at 57 locations with good visibility, equally distributed along the road network and six kilometers apart to minimize counting individuals twice. We surveyed during calm and clear nights, at least half an hour after nightfall and before dawn. During call-ups, two observers scanned for predators using thermal night vision goggles (Pulsar Quantum XQ50), and recorded every carnivore approaching or responding acoustically. At two locations, however, we were surprised by a storm and had to abort the survey.

\subsubsection{Aerial surveys}

We benefited from aerial surveys conducted by the ACC to identify groups of pastoralists that illegally entered the reserve. During the dry season of 2016/2017 (Survey B), a pilot and an observer took off daily with an ultra-light aircraft (ULM) and recorded all sightings of livestock and herder camps. Here we used the data from $70450 \mathrm{~km}$ of surveys conducted between November 2016 and May 2017 (Fig. A1).

\subsection{Density estimates}

We estimated population densities from track counts using the model for clay soils of Funston et al. (2010) for apex predators, and the Formozov-Malyshev-Pereleshin (FMP) formula (Chelintsev, 1995; Stephens et al., 2006) for apex predators and large herbivores. As detailed in Text A2, we estimated the necessary average group sizes for each species from all direct sightings and camera trap events. We further used radio collar data to estimate daily travel distances for giant elands, hartebeests and roan, and use literature values for all other species (Stark, 1986; Fuller and Kat, 1990; Klaus-Hügi et al., 2000; Fischer and Linsenmeyer, 2001; Kolowski, 2007; Wilson and Mittermeier, 2009; Stratford and Stratford, 2011; Woodroffe et al., 2012; Pomilia, 2015).

We further used DISTANCE.V6 (Thomas et al., 2010) to estimate densities from direct sightings for all mammals with at least 10 sightings.

Finally, we estimated densities from call-ups as $d_{i}=\frac{n_{i} r_{i}}{A_{i}}$,

where $n_{i}$ is the number of animals responding, $A_{i}$ the area surveyed and $r_{i}$ the response rate. Because of the thick vegetation and because both species surveyed were skittish and not habituated to cars, we could not conduct local calibration experiments. We thus used the average response distance and response rate among estimates from similar habitats for lions (Ogutu and Dublin, 1998; Kiffner et al., 2008; Ferreira and Funston, 2010; Cozzi, 2013) and spotted hyenas (Creel and Creel, 2002; Graf et al., 2009; Mills, 2001), resulting in a surveyed area of $27.0 \mathrm{~km}^{2}$ 

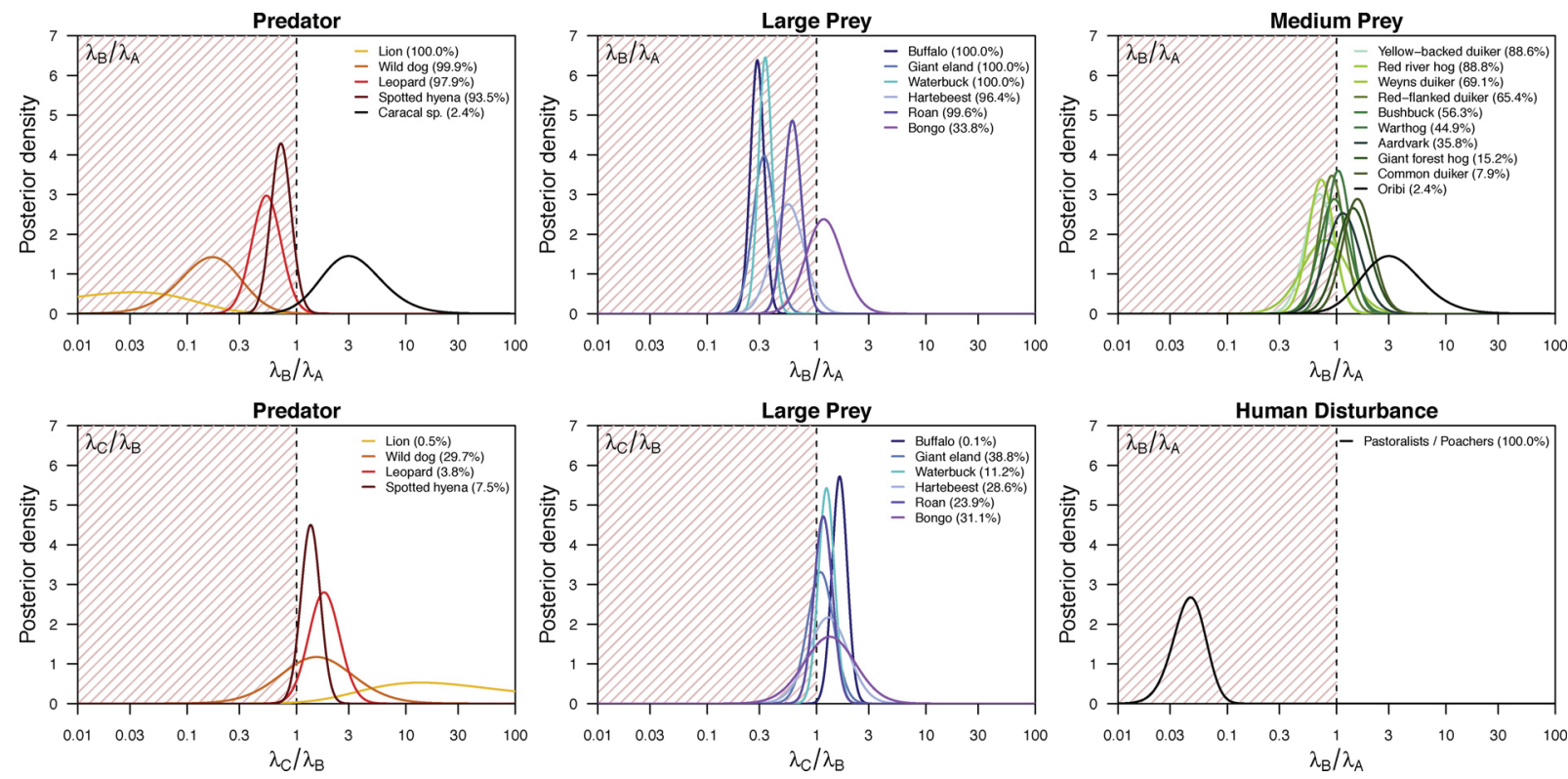

Fig. 2. Posterior estimates of the changes in population densities or densities of human disturbance between surveys A and B based on track count and (predators, large prey and human disturbance) or (medium prey) camera trap surveys. Low $\varphi=\lambda_{B} / \lambda_{A}$ indicate a reduction in densities in survey B compared to survey A. Species in the legend are sorted from lowest to highest posterior mode. Percentages indicate the posterior probability $P(\varphi<1 \mid D)$ of a reduction.

and $28.3 \mathrm{~km}^{2}$, and a response rate of 0.61 and 0.52 , respectively.

\subsubsection{Carrying capacities of apex predators}

We followed Hayward et al. (2007) to estimated potential carrying capacities of apex predators from the inferred biomass of likely prey species (Table A1, Text A3).

\subsection{Inference of change in population densities}

We quantify the change in population densities while accounting for the uncertainty associated with density estimates. By focusing on change, our method allows to naturally combine data from multiple survey methods. Let $x_{i}$ and $x_{i}^{\prime}$ denote vectors of observed counts obtained during two different survey periods using methods $i=1, \ldots, I$ with known efforts $s_{i}, s_{i}^{\prime}$. We assume that these counts are Poisson distributed with means $\lambda_{i} s_{i}$ and $\lambda_{i}^{\prime} s^{\prime}{ }_{i}$, respectively, and our interest lies in inferring the change in detection rates (i.e. relative risks) $\lambda_{i}^{\prime} / \lambda_{i}$ reflective of a change in the population density. In contrast to the detection rates, relative risks are independent of the survey method and hence $\lambda_{i}^{\prime}=\phi \lambda_{i}$ for a fixed parameter $\phi$. Thus,

$x_{i} \sim P\left(\lambda_{i} s_{i}\right), x_{i}^{\prime} \sim P\left(\phi \lambda_{i} s_{i}^{\prime}\right)$.

To infer $\phi$, we condition on the number of observations $n_{i}=x_{i}+x_{i}^{\prime}$. The conditional distribution of $x=\left(x_{1}, \ldots, x_{I}\right)$ given $n=\left(n_{1}, \ldots, n_{I}\right)$ is

$L(x \mid \phi, n) \propto \prod_{i=1}^{I} p_{i}(\phi)^{x_{i}}\left(1-p_{i}(\phi)\right)^{n_{i}-x_{i}}$,

where

$p_{i}(\phi)=\frac{\lambda_{i} s_{i}}{\lambda_{i} s_{i}+\phi \lambda_{i} s_{i}^{\prime}}=\left(1+\frac{s_{i}^{\prime}}{s_{i}} \phi\right)^{-1}$

is the probability that an event occurred during the first survey. Observe that by conditioning we get rid of the nuisance parameter $\lambda_{i}$. We chose the non-informative Jeffrey's prior for $\phi$ (Text A4) and obtained posterior estimates by numerical evaluation. An implementation of this method in $\mathrm{R}$ is available as a Supplementary File.

\subsection{Spatial distributions}

We quantified the distribution of normalized event densities $d_{c}$ of track counts and aerial records of Survey B on a $10 \mathrm{~km}$ x $10 \mathrm{~km}$ grid, but limited the analysis to cells surveyed for at least $5 \mathrm{~km}$ of transect or $100 \mathrm{~km}$ of ULM flight. Each cell was classified as within or outside the core zone based on where more effort was spent. To test for differences in event densities within or outside the core zone, we calculated the rank sum $R_{\text {in }}$ of each class using average ranks for ties. We then calculated rank sums $R_{\text {in }}$ for $10^{6}$ data sets generated under the null hypothesis of equal densities by randomly distributing the track counts multinomially according to per cell survey efforts. One-sided p-values were obtained as the fraction of simulations with larger (or smaller) rank sums than those observed. We tested for differences between response rate at call-up locations inside and outside of the core zone under a multinomial distribution with equal response rates among locations.

\subsection{Interviews}

To learn about the origin, organization and activities of pastoralists in and around the ACC, we conducted voluntary, in-depth interviews in March 2016 (Survey B) with foreign herders of four groups, four foreign merchants, four local herders and the responsible of the main cattle market in Nzako (Text A5). All interviews were conducted in Fulfulde or Arabic with unrelated people at different locations between the city Nzako in the West, the Chinko River in the East, the Mbari and Mbutu River in the north and the village Fodé in the South (Fig. A2). All participants were made aware that their responses will help to identify major threats to the ACC and to find strategies to manage those. To respect and protect the privacy of all participants, we do not provide individual responses and only summarize commonly voiced aspects. During 2018 and 2019 (Survey C), unarmed rangers of the ACC reached out to pastoralist groups around the park to minimize conflict and to inquire about their origin.

\section{Results}

\subsection{Sharp decline of lions and African wild dogs}

Track count and camera trap surveys indicated a sharp decline of lions between surveys. In Survey A, we recorded six lion tracks in four locations and captured at least six lions (three adult females, two 
Table 1

Estimates of population densities and absolute numbers of apex predators and preferred prey species in the study area of approximately $6000 \mathrm{~km}{ }^{2}$.

\begin{tabular}{|c|c|c|c|c|c|}
\hline \multirow[b]{2}{*}{ Species } & \multirow[b]{2}{*}{ Method } & \multicolumn{2}{|l|}{2012} & \multicolumn{2}{|l|}{2017} \\
\hline & & $\mathrm{N} / 100 \mathrm{~km}^{2}$ & $\mathrm{~N}$ in $6,000 \mathrm{~km}^{2}$ & $\mathrm{~N} / 100 \mathrm{~km}^{2}$ & $\mathrm{~N}$ in $6,000 \mathrm{~km}^{2}$ \\
\hline \multirow[t]{4}{*}{ Lion } & Density (FMP) & 0.2 & 13 & 0.0 & 0 \\
\hline & Density (Funston) ${ }^{\mathrm{a}}$ & 2.8 & 170 & 0.0 & 0 \\
\hline & Density (Call-up) & - & - & 0.4 & 22 \\
\hline & Carrying Capacity & 6.0 & 360 & 4.0 & 240 \\
\hline \multirow[t]{3}{*}{ Wild dog } & Density (FMP) & 2.7 & 160 & 0.4 & 26 \\
\hline & Density (Funston) ${ }^{\mathrm{a}}$ & 10.2 & 614 & 1.6 & 96 \\
\hline & Carrying Capacity & 1.9 & 114 & 1.1 & 66 \\
\hline \multirow[t]{3}{*}{ Leopard } & Density (FMP) & 1.6 & 97 & 0.8 & 50 \\
\hline & Density (Funston) ${ }^{\mathrm{a}}$ & 5.8 & 346 & 3.2 & 191 \\
\hline & Carrying Capacity & 4.9 & 294 & 3.2 & 192 \\
\hline \multirow[t]{4}{*}{ Spotted hyena } & Density (FMP) & 1.7 & 101 & 1.4 & 83 \\
\hline & Density (Funston) ${ }^{\mathrm{a}}$ & 6.4 & 382 & 5.2 & 311 \\
\hline & Density (Call-up) & - & - & 4.4 & 267 \\
\hline & Carrying Capacity & 7.5 & 449 & 5.3 & 317 \\
\hline Buffalo & Density (FMP) & 39.4 & 2366 & 10.3 & 616 \\
\hline Waterbuck & Density (FMP) & 20.0 & 1199 & 5.4 & 322 \\
\hline Giant eland & Density (FMP) & 8.9 & 537 & 3.2 & 189 \\
\hline Hartebeest & Density (FMP) & 0.9 & 53 & 0.5 & 29 \\
\hline Roan & Density (FMP) & 7.6 & 454 & 5.8 & 345 \\
\hline Bongo & Density (FMP) & 2.6 & 156 & 1.3 & 78 \\
\hline
\end{tabular}

${ }^{\text {a }}$ Regression model of Funston et al. (2010), see text.
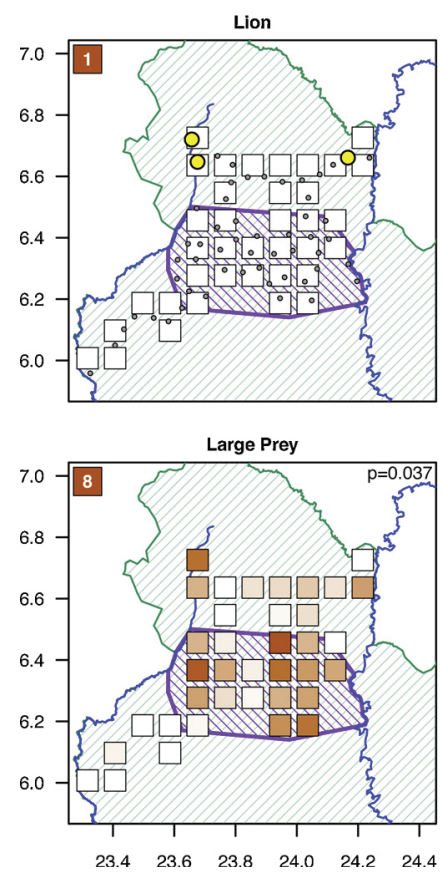

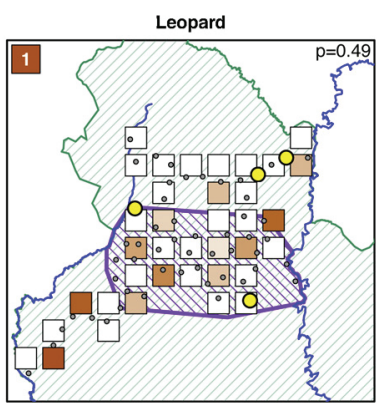

Medium Prey

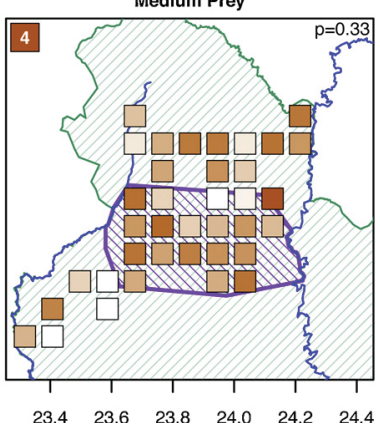

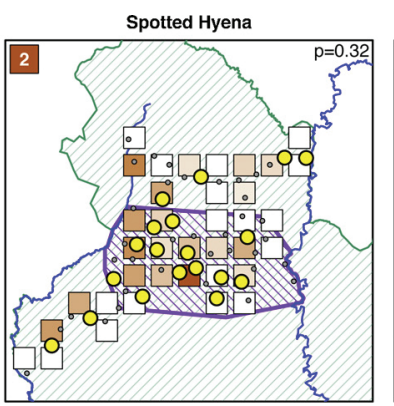

Livestock and Herders (tracks)

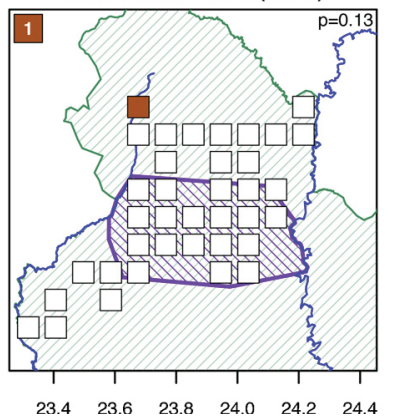

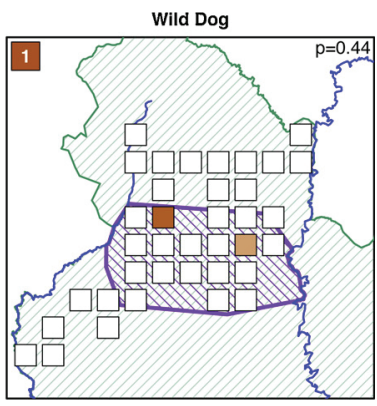

Livestock and Herders (aerial)

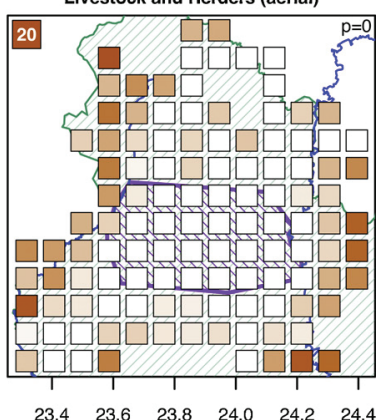

Fig. 3. Spatial distribution of apex predators, prey and signs of pastoralist inferred from track count and aerial surveys in 2017 (Survey B) against the ACC (green), the core zone of 2017 (purple) and the two major rivers Mbari (west) and Chinko (east). Shown are the density of events per km, indicated in shades of red, for all $10 \mathrm{~km} \times 10 \mathrm{~km}$ grid cells surveyed for at least $5 \mathrm{~km}$ of transect or $100 \mathrm{~km}$ of ULM flight. The darkest shade indicates the seconded highest density, rounded up to the next integer value. Significance (p-values) of the difference in event densities within and outside the core zone is indicated in top-right corners. For lions, leopards and spotted hyenas, dots indicate call-up locations with (large yellow) or without (small grey) observations.

subadult males, one juvenile) in five camera traps. In contrast, no evidence for lions was found with either method in Survey B, despite a larger effort and despite having mounted cameras at all locations that recorded lions in Survey A. Using a Bayesian model combining both data sets and accounting for differences in effort, we could rule out a stable density $(\mathrm{P}(\varphi<1.0)=1.000)$ and estimate a reduction of lions to less than $3 \%$ of their density in Survey A $(\varphi=0.026$, Fig. 2 , A2, Table 1). Systematic call-up surveys in Survey B confirmed the virtual absence of lions, which responded at only three locations at the northernmost edge of the study area, and only vocally (Fig. 3).

We estimated a similarly sharp reduction for African wild dogs, of which we captured one individual on camera and recorded 22 tracks in eight locations in Survey A, but did not capture any individual and found only seven tracks in three locations in Survey B. These data is also not consistent with a stable density $(\mathrm{P}(\varphi<1.0)=0.999)$ and we estimate a reduction of wild dogs to $17 \%$ of their density in Survey A $(\varphi=0.166$, Fig. 2, A2, Table 1$)$.

In contrast, leopards and spotted hyenas remained relatively common during Survey B: we captured both species at four camera traps each, recorded tracks at 17 and 51 locations, respectively, and had 40 hyenas responding at 19 call-up locations (Fig. 3). Surprisingly, we also observed six leopards at four call-up stations, despite broadcasting 
stimuli not generally recommended to attract leopards (Fig. 3). Using the regressions of Funston et al. (2010) for clay soils, our track counts translate to about three leopards and five spotted hyenas per $100 \mathrm{~km}^{2}$ as of 2017 (Table 1). Nonetheless, we estimated a striking reduction to about $50 \%(\varphi=0.507, \mathrm{P}(\varphi<1.0)=0.986)$ and $70 \%(\varphi=0.711, \mathrm{P}$ $(\varphi<1.0)=0.939)$ of the density of leopards and spotted hyenas in Survey A, respectively (Fig. 2, A2). Interestingly, the three felids from the Caracal-lineage for which we had only camera trap data increased significantly $(\mathrm{P}(\varphi>1.0)=0.976)$. We did not find any evidence of cheetah but given two recent sightings reported by independent trophy hunters, its presence at a very low density cannot be ruled out.

\subsection{Decline of large, but not medium sized prey}

With the exception of the bongo antelope $(\mathrm{P}(\varphi<1.0)=0.338)$, all large herbivores surveyed declined between our two surveys ( $P$ $(\varphi<1.0) \geq 0.964$, Table 1, Fig. 2, A2). Among them, the buffalo, the giant eland and the waterbuck declined most strongly ( $\varphi$ between 0.288 and 0.328$)$, while the hartebeest $(\varphi=0.549)$ and roan ( $\varphi=0.602)$ declined more moderately. The medium sized grazer Kob antelope, still occasionally spotted in Survey A (three sightings of multiple individuals, one camera trap event), likely went locally extinct (no record in Survey B, $\mathrm{P}(\varphi<1.0)=0.997)$. In contrast, all medium sized prey surveyed did not or only marginally decline. The strongest evidence for a decline we found for the red river hog ( $\mathrm{P}(\varphi<1.0)$ $=0.934)$ and the yellow backed duiker $(\mathrm{P}(\varphi<1.0)=0.872)$, which declined to about $70 \%$ of their densities of 2012 (Fig. 2). No evidence for a decline was found for the Weyn's duiker, the bushbuck, the warthog and the aardvark $(\mathrm{P}(\varphi<1.0)$ between 0.691 and 0.358$)$, and the data is even suggestive of an increase of the giant forest hog $(\varphi=1.385, \mathrm{P}(\varphi>1.0)=0.848)$, the common duiker $(\varphi=1.542, \mathrm{P}$ $(\varphi>1.0)=0.921)$ and in particular the oribi $(\varphi=2.996, P$ $(\varphi>1.0)=0.976)$.

\subsection{Carrying capacity of apex predators}

The estimated carrying capacity of lions exceeded estimated densities in both surveys (Table 1). The density estimated with the call-up method, for instance, was only one tenth of the estimated carrying capacity of that year ( 0.4 versus 4.0$)$. Importantly, even a carrying capacity estimate based on the buffalo alone, the most preferred prey of lions (Ruggiero, 1991), exceeded estimated densities six-fold (2.4 versus 0.4 in Survey B).

Densities of leopards and spotted hyenas were much closer to estimated carrying capacities, and wild dogs appeared to exceed their estimated carrying capacity (Table 1). But we likely underestimated these carrying capacities considerably because we had no data on many important prey species. For leopards and wild dogs, for instance, less than $40 \%$ of all known and occurring prey species contributed to carrying capacities estimates (Table A1).

\subsection{Effective law enforcement}

During Survey A, we recorded 81 and 32 illegal activities using track count and camera trap surveys, respectively: mainly livestock grazing $(82 \%)$, some poaching predominantly by pastoralists $(17 \%)$, and rarely mining (1\%). On average, we recorded such an event every $6.2 \mathrm{~km}$ of transect and at $36 \%$ of all camera trap locations. Alarmingly, these activities affected $68 \%$ of all $10 \times 10 \mathrm{~km}$ cells surveyed, and not only those closest to settlements or roads (Fig. A3).

As of 2015, African Parks enforces strict protection in most of the study area. Consequently, and despite larger effort, we recorded about 95\% fewer illegal activities in Survey B $(\mathrm{P}(\varphi<1.0)=1.000$, $\varphi=0.045$ ): only six along transects and a single event on camera traps (Fig. 2, A2).

\subsection{Core zone protects most mammals, but not lions}

We found a much lower density of livestock and herders ( $\mathrm{p}<10^{-6}$, aerial data) and a higher density of large herbivores $(\mathrm{p}=0.038$, track counts) inside than outside the actively managed core zone. In addition, the densities of medium prey, leopard, spotted hyena and wild dogs, while not significant, were consistently higher inside the core zone. This is in stark contrast to the inferred spatial distribution of lions, for which we recorded all three responses to call-ups outside the core zone ( $p=0.055)$ in areas with a high density of livestock (Fig. 3).

\subsection{Suggestion of recovery after enlargement of core zone}

The ACC increased the protected core zone in 2018 and 2019 considerably. Our track count survey in the dry season of 2019 (Survey C, Fig. 2) confirmed the success of this strategy with strong evidence for an increase in the density of lions (four tracks, $\mathrm{P}(\varphi>1.0)=0.995$, $\varphi=21.445)$ and leopards $(20$ tracks, $\mathrm{P}(\varphi>1.0)=0.962$, $\varphi=1.788$ ), and somewhat weaker evidence for spotted hyenas (45 tracks, $\mathrm{P}(\varphi>1.0)=0.925, \varphi=1.356)$ and wild dogs ( 3 tracks, $\mathrm{P}$ $(\varphi>1.0)=0.703, \varphi=1.514)$. Similarly, we inferred a small increase in the densities of all large prey species $(\mathrm{P}(\varphi>1.0)>0.611$, $\varphi>1.086)$, most notably for buffalos $(\mathrm{P}(\varphi>1.0)=0.999$, $\varphi=1.630)$.

\subsection{Origin and structure of pastoralists in the eastern CAR}

Herder groups consisted of 20-50 people and up to seven herds of 100-150 cattle each, mounting to at least 10,000 cattle within the ACC in March 2015. Most groups belonged to the ethnic group of the Fulani Mbororo herders and spoke Fulfulde and Arabic. Of the 157 groups intercepted by the ACC in 2018 and 2019 (Survey C), all self-identified as Danedji from Darfur and 125 (80\%) indicated their origin close to one of three centers: 47 to Tullus (500 km from the ACC), 45 to Tomat $(690 \mathrm{~km})$ and 33 to Soungou $(460 \mathrm{~km})$. They reached the ACC within about 45 days either along the Kotto, Mbutu and Mbari Rivers, or along the Chinko to the Ali River.

According to the 14 herder groups interviewed (Survey B), groups stayed rarely longer than two days in one place and included some family members (women, children and elderly), while others took care of agricultural activities back home. Young adults were generally hired and paid one 2-year-old cow per four months, corresponding to an annual income of 150000 Central African Francs (XAF). Livestock owners earn about 300000 XAF by selling cattle.

We also interviewed four merchants that sold veterinary drugs and basic necessities (e.g. salt, sugar, millet, tea, or makeshift tents) to herders, in exchange for livestock and rarely money. All of those spoke Arabic and identified as Ta'isha or Rizeigat from around Am Dafok on the Sudan / CAR border, were heavily armed and also engaged in poaching, with some even mentioning poaching as the main reason to visit the region. They indicated as main targets valuable products such as elephant tusks and leopard skins for markets for instance in Am Dafok. However, due to the scarcity of elephants in the region, the main income stems from bushmeat of large herbivores, namely giant eland, buffalo, hartebeest and waterbuck, which they smoked and sold on markets in Sudan or to herders. Interestingly, herders indicated not to consume bushmeat themselves, but to trade it with local mining communities, on the local market, or in the Sudan, using their livestock for transportation. With the increasing scarcity of larger animals, merchants also exploited honey of wild bees and collected bark and wood of valuable trees and shrubs.

All foreign people interviewed depended on powerful traditional Sudanese leaders to which they had to report their activities in the CAR and pay an annual fee (sofal), which was one cow per herd and per 40 employees for herders. Armed men claimed that their weapons were registered with Sudanese authorities and commissioned for their trip. 


\subsection{Threats to livestock}

Herders interviewed (Survey B) mentioned diseases as the major threat to their livestock. Trypanosomiasis and bovine lung plague (CBPP) urged herders to apply prophylaxis as well as immediate treatments in the field. Whenever possible, veterinary products were brought from Sudan, but also bought from merchants or at local markets, where it was more expensive.

The second largest issue was cattle thieves, which operated on the entire route. To fight thieves, herder mentioned to carry weapons (at least five assault rifles per group) and to hire merchants for protection, and all experienced heavy fights. The militarization of pastoralist convoys and the fact that many merchants acquired cattle through trade makes a clear distinction between "true herders" and "true poachers" very difficult in the field.

The third most important threat to livestock was wildlife, especially snakes and the large carnivores spotted hyenas, lions and leopards. Multiple herders mentioned that they don't hesitate to poison predators by undeclared methods, but instated to do so only after an attack on livestock.

\section{Discussion}

\subsection{Influx of pastoralists drive apex predator extinction}

Here we report a recent decline of apex predators in a remote part of the Eastern CAR Wilderness. Within few years, lions and African wild dogs disappeared in many localities, and leopards and spotted hyenas declined to $50 \%$ and $70 \%$ of their initial density. This decline coincides with an influx of transhumant pastoralist in this previously uninhabited region protected as hunting zones and nature reserves. Direct and indirect evidence suggest that this influx of pastoralists was the main driver of the reduction of apex predators.

\subsubsection{Direct killing of apex predators by pastoralists}

Pastoralists appeared to have systematically persecute apex predators, and in particularly lions. Indeed, we frequently found poisoned cadavers (cattle) and trophy hunters reported multiple poisoned lions and hyenas. In 2016, law enforcement personnel of the ACC confiscated large amounts of poison suitable to kill apex predators at many illegal pastoralist camps. During interrogations and interviews, some pastoralists readily admitted to kill lions to protect their livestock. Several pastoralist, and in particular accompanying merchants, further admitted to selective hunting of leopards for their highly valuable skin. Local ACC staff further reported a market for lion fur in the CAR, suggesting that pastoralists and poachers might kill lions also opportunistically for trade. Finally, a management strategy focused on keeping pastoralist groups outside an enlarged core zone resulted in an increase in the density of all apex predators. Direct illegal killing and legal trophy hunting prior to 2012 might also explain why lions never approached call-up stations but only responded vocally.

\subsubsection{Limited effect of trophy hunting, ivory poaching and mining}

Localized trophy hunting was practiced within the study region from 2006 until 2015. However, neither African wild dogs nor spotted hyenas were ever hunted, and the last lions were killed in 2011. In addition, off-takes of leopards ( 30 males, seven or less per year) and lions (six males, two or less per year) were always equal or lower than sustainable hunting quotas for zones of this size, even when adjusting for their low densities (Caro et al., 2009; Packer et al., 2011; Bouché et al., 2016).

Groups of well-armed Sudanese ivory poachers were active in the region for the past 40 years and peaked in the 1980's (Roulet et al., 2007). Due to the crash of local elephant populations (Fay, 1991) with less than 100 individuals left in 2017, ivory poachers were present in very low numbers only. Despite their still detrimental effect on the critically endangered local elephant populations, their impact on other wildlife was thus limited.

Finally, the only illegal mining sites in the ACC known to African Parks were very localized along rivers close to the western park border. Meat poaching by miners was hence unlikely to have a measurable effect on population densities in the region.

\subsubsection{Sufficient prey biomass to support apex predators}

Prey availability is a known limiting factor for large carnivores (Ripple et al., 2014) and doubtlessly decreased in the eastern CAR over the past decades. The observed recent decline in apex predators, however, is unlikely explained by a reduction of their food source alone. Indeed, many important prey species (mainly medium sized herbivores) were not or only marginally reduced. And even the large herbivores most strongly reduced (the buffalo, giant eland and waterbuck) easily support a much larger population of lions themselves. However, the documented decline of prey species will likely limit apex predators in near future, unless halted or reversed.

\subsection{Land-use change alters community structure}

As we documented here for the Caracal-lineage, the loss or reduction of apex predators may result in the increase of medium sized carnivores that become functional top predators (Ripple et al., 2014). Such changes likely affect the entire food chain by shifting the competition among carnivores and the predation risks of many herbivores and smaller animals. As an example, consider the pronounced increase of the oribi $(>3 \mathrm{x})$, a medium-sized, open-grassland species that is opportunistically hunted by all apex predators (Table A1), but of limited value to meat poachers.

Large herbivores probably benefited most from the reduction of apex predators through reduced predation, but they also suffered most from the increased poaching pressure. However, by selectively targeting savanna species, rather than secretive forest dwellers, pastoralists alter the community structure of large herbivores. As a striking example consider the giant eland and the bongo antelope, two closely related species of similar size, but with populations densities that were very differently affected. Indeed, interviews with pastoralists identified giant elands as a focal target and in most pastoralist camps inspected by ACC rangers, parts of recently killed giant elands were found, often among remains of buffalo or waterbuck. In contrast, no skins of bongo were found, and the only bongo carcasses with bullet injuries were recorded as rotten complete bodies hidden in thick vegetation. It is interesting to note that this differential effect on large savanna browsers is characteristic of hunting by transhumant pastoralists. The main strategies used by local and international meat and ivory poachers as well as poaching teams of illegal mining communities are ambush poaching methods in forest clearings, snaring with metal cables, night hunts with torches or forest hunts with dogs, which are all very efficient to kill secretive forest dwellers such as bongo antelopes.

\subsection{Management considerations}

Despite the recent decline of apex predator populations, the eastern CAR remains a promising area for the long-term conservation of these iconic species. Not only is the area with pristine habitat large, it also boosts a still relatively high prey biomass and is likely one of the last potential strongholds for the northern / western lineage of many savanna species, especially lions (Bertola et al., 2016). Finally, and as our last survey indicated, the remaining apex predator populations are likely of sufficient strength to naturally recover if their major threats can be mitigated.

The increased use of the wilderness as pasture land is the major threat for multiple reasons: First, pastoralists are directly killing apex predators. Second, their meat poaching reduces the available prey biomass. Third, the high density of livestock leads to habitat destruction 
and increases the risk of disease transmission to wildlife (Bouché et al., 2012). Finally, many drugs used by herders for veterinary care (e.g. diclofenac and broad-spectrum antibiotics) are highly detrimental to the scavenger community (Naidoo et al., 2009).

To mitigate these threats, the ACC keeps a core zone devoid of any human disturbance, while tolerating limited land-use in a buffer zone surrounding it. Our surveys indicated that this strategy protected most prey and apex predator populations already at a small core zone of 2 $300 \mathrm{~km}^{2}$. The striking exceptions are lions, which appeared to be lured out of this core zone by large cattle herds, where they got killed by pastoralists defending their livestock. Only a larger core zone is thus able to protect lions in the ACC.

However, we strongly urge for a management plan for the entire eastern CAR that foresees corridors for transhumant pastoralists while ensuring the connectivity of the faunal reserves Zémongo and YataNgaya and the national park André-Felix, even if they are not currently managed. If tackled quickly, there is a unique chance of conserving a complex ecosystem encompassing the entire drainage system of the Chinko and the headwaters of six other major rivers, including the Yata, which supplies the chronically dry Sahel and Lake Chad.

On a more general note, our findings suggest that pastoralist societies can constitute a major threat to large savanna herbivores and apex predators. We thus caution against the transformation of protected areas or hunting zones into pasture land, unless such a land-use change can be carefully managed and strictly controlled.

\section{Declaration of Competing Interest}

The authors declare that they have no known competing financial interests or personal relationships that could have appeared to influence the work reported in this paper.

\section{Acknowledgments}

This survey was supported by the Big Cats Initiative of National Geographic (grant number B14-15 to T.A.) and PANTHERA. We would like to thank Philipp Henschel and Gabriele Cozzi for their useful advice in experimental planning, as well as the African Parks Network, its hard-working Staff, and in particular D. Simpson and C. Ganiere, for their data obtained through collaring and aerial surveys and the fruitful collaboration. Special thanks go to the Chinko Research Team: V. Pandi, J. Wakassa, H. Gangbo, F. Magraba, K. Yaya, O. Sado, A. Wiga, A. Gbandbo, N. Bangali, E. Lango, S. Wagalet, G. Siguindo.

\section{References}

Aebischer, T., et al., 2017. First quantitative survey delineates the distribution of chimpanzees in the Eastern Central African Republic. Biol. Conserv. 213, 84-94.

Bauer, H., et al., 2015. Lion (Panthera leo) populations are declining rapidly across Africa, except in intensively managed areas. Proc. Natl. Acad. Sci. 112 (48), 14894-14899.

Bertola, L.D., et al., 2016. Phylogeographic patterns in Africa and high resolution delineation of genetic clades in the lion (Panthera leo). Sci. Rep. 6, 30807.

Blom, A., Yamindou, J., Prins, H.H.T., 2004. Status of the protected areas of the Central African Republic. Biol. Conserv. 118, 479-487.

Bohm, T., Höner, O.R., 2015. Crocuta crocuta. The IUCN Red List of Threatened Species 9: 2015-3.

Bouché, P., et al., 2012. Game over! Wildlife collapse in northern Central African Republic. Environ. Monit. Assess. 184 (11), 7001-7011.

Bouché, P., et al., 2016. Embargo on lion hunting trophies from West Africa: an effective measure or a threat to lion conservation? PloS One 11 (5), e0155763.

Boulvert, Y., 1985. Carte phytogéographique de la République Centrafricaine. ORSTOM (Office de la recherche scientifique et technique Outre-Mer).

Brandlová, K., et al., 2018. Chinko/Mbari drainage basin represents a conservation hotspot for Eastern Derby eland in Central Africa. Afr. J. Ecol. 56 (2), 194-201.

Brugière, D., Chardonnet, B., Scholte, P., 2015. Large-scale extinction of large carnivores (lion Panthera leo, cheetah Acinonyx jubatus and wild dog Lycaon pictus) in protected areas of West and Central Africa. Tropical Conservation Science 8 (2), 513-527.

Caro, T.M., et al., 2009. Animal breeding systems and big game hunting: models and application. Biol. Conserv. 142 (4), 909-929.

Chelintsev, N.G., 1995. Mathematical principles of winter censuses of mammals.
Byulleten Moskovskogo Obschestva Ispytatelei Prirody 100, 3-19.

Cozzi, G., et al., 2013. Density and habitat use of lions and spotted hyenas in northern Botswana and the influence of survey and ecological variables on call-in survey estimation. Biodivers. Conserv. 22 (12), 2937-2956.

Creel, S., Creel, N.M., 2002. The African Wild Dog: Behavior, Ecology, and Conservation. Princeton University Press.

Davies-Mosert, H., Mills, M.G.L., Mcdonald, D.W., 2015. The demography and dynamics of an expanding, managed African wild dog metapopulation. Afr. J. Wildl. Res. 45 (2), 258-273.

Fay, J.M., 1991. An elephant (Loxodonta africana) survey using dung counts in the forests of the Central African Republic. J. Trop. Ecol. 7 (1), 25-36.

Ferreira, S.M., Funston, P.J., 2010. Estimating lion population variables: prey and disease effects in Kruger National Park, South Africa. Wildl. Res. 37 (3), 194-206.

Fick, S.E., Hijmans, R.J., 2017. Worldclim 2: New 1-km spatial resolution climate surfaces for global land areas. Int. J. Climatol.

Fischer, F., Linsenmair, K.E., 2001. Spatial and temporal habitat use of kob antelopes (Kobus kob kob, Erxleben 1777) in the Comoé National Park, Ivory Coast as revealed by radio tracking. Afr. J. Ecol. 39 (3), 249-256.

Fuller, T.K., Kat, P.W., 1990. Movements, activity, and prey relationships of African wild dogs (Lycaon pictus) near Aitong, southwestern Kenya. Afr. J. Ecol. 28 (4), 330-350.

Funston, P.J., et al., 2010. Substrate and species constraints on the use of track incidences to estimate African large carnivore abundance. J. Zool. 281 (1), 56-65.

Fynn, R.W., et al., 2016. Strategic management of livestock to improve biodiversity conservation in African savannahs: a conceptual basis for wildlife-livestock coexistence. J. Appl. Ecol. 53 (2), 388-397.

Giordano, A.J., Tumenta, P.N., de Iongh, H.H., 2017. Camera-trapping confirms unheralded disappearance of the leopard (Panthera pardus) from Waza National Park, Cameroon. Afr. J. Ecol. 55 (4), 722-726.

Graf, J.A., et al., 2009. Heterogeneity in the density of spotted hyaenas in HluhluweiMfolozi Park, South Africa. Acta Theriol. 54 (4), 333-343.

Harris, N.C., et al., 2019. First camera survey in Burkina Faso and Niger reveals human pressures on mammal communities within the largest protected area complex in West Africa. Conserv. Lett In press.

Hayward, M.W., 2006. Prey preferences of the spotted hyaena (Crocuta Crocuta) and degree of dietary overlap with the lion (Panthera leo). J. Zool. 270 (4), 606-614.

Hayward, M.W., Kerley, G.I., 2005. Prey preferences of the lion (Panthera leo). J. Zool 267 (3), 309-322.

Hayward, M.W., et al., 2006a. Prey preferences of the African wild dog Lycaon pictus (Canidae: Carnivora): ecological requirements for conservation. J. Mammal. 87 (6), $1122-1131$.

Hayward, M.W., et al., 2006b. Prey preferences of the leopard (Panthera pardus). J. Zool. 270 (2), 298-313.

Hayward, M.W., et al., 2006c. Prey preferences of the cheetah (Acinonyx jubatus) (Felidae: Carnivora): morphological limitations or the need to capture rapidly consumable prey before kleptoparasites arrive? J. Zool. 270 (4), 615-627.

Hayward, M.W., O’Brien, J., Kerley, G.I., 2007. Carrying capacity of large African predators: predictions and tests. Biol. Conserv. 139 (1-2), 219-229.

Hickisch, R., Aebischer, T., 2013. Distribution Update. Evidence of African Wild Dogs in the Central African Republic. The IUCN/SSC Canid Specialist Group ISSN 1478 2677.

Jacobson, A.P., et al., 2016. Leopard (Panthera pardus) status, distribution, and the research efforts across its range. PeerJ 4, e1974.

Kiffner, C., et al., 2008. Response of lions (Panthera leo LINNAEUS 1758) and spotted hyaenas (Crocuta Crocuta ERXLEBEN 1777) to sound playbacks. Afr. J. Ecol. 46 (2), 223-226.

Klaus-Hügi, C., Klaus, G., Schmid, B., 2000. Movement patterns and home range of the bongo (Tragelaphus eurycerus) in the rain forest of the Dzanga National Park, Central African Republic. Afr. J. Ecol. 38 (1), 53-61.

Kolowski, J.M., et al., 2007. Daily patterns of activity in the spotted hyena. J. Mammal. 88 (4), 1017-1028.

Lamarque, F., et al., 2009. Human-Wildlife Conflict in Africa: Causes, Consequences and Management Strategies (No. 157). Food and Agriculture Organization of the United Nations (FAO).

Macdonald, D.W., et al., 2017. Lions, trophy hunting and beyond: knowledge gaps and why they matter. Mam. Rev. 47, 247-253.

Malith, W.C., Ahmed, O.M., 2017. Environment and conflict reflection on Sudan and South Sudan. Disaster, Risk and Vulnerability Conference 2017113.

McGahey, D., Davies, J., Hagelberg, N., Ouedraogo, R., 2014. Pastoralism and the Green Economy-a Natural Nexus. IUCN and UNEP, Nairobi $x+58$.

Mésochina, P., Shéhou, O., 2009. Cartographie participative des activités humaines dans le Haut Mbomou. Fondation IGF, Bangui, pp. 41.

Mésochina, P., et al., 2010. Statut de conservation du lion (\# Panthera leo\# Linnaeus, 1758) en République Centrafricaine.

Mills, M.G.L., Juritz, J.M., Zucchini, W., 2001. Estimating the size of spotted hyaena (Crocuta crocuta) populations through playback recordings allowing for non-response. Animal Conservation 4 (4), 335-343.

Naidoo, V., et al., 2009. Veterinary diclofenac threatens Africa's endangered vulture species. Regul. Toxicol. Pharmacol. 53 (3), 205-208.

Niamir-Fuller, M., et al., 2012. Co-Existence of Wildlife and Pastoralism on Extensive Rangelands: Competition or Compatibility?.

Ogutu, J.O., Dublin, H.T., 1998. The response of lions and spotted hyaenas to sound playbacks as a technique for estimating population size. Afr. J. Ecol. 36 (1), 83-95.

Packer, C., et al., 2011. Effects of trophy hunting on lion and leopard populations in Tanzania. Conserv. Biol. 25 (1), 142-153.

Packer, C., et al., 2013. Conserving large carnivores: dollars and fence. Ecol. Lett. 16, 635-641 2013 
Pomilia, M.A., McNutt, J.W., Jordan, N.R., 2015. Ecological predictors of African wild dog ranging patterns in northern Botswana. J. Mammal. 96 (6), 1214-1223.

Pykälä, J., 2000. Mitigating human effects on European biodiversity through traditional animal husbandry. Conserv. Biol. 14 (3), 705-712.

Riggio, J., et al., 2013. The size of savannah Africa: a lion's (Panthera leo) view Biodivers. Conserv. 22 (1), 17-35.

Ripple, W.J., et al., 2014. Status and ecological effects of the world's largest carnivores. Science 343 (6167), 1241484.

Roulet, P.A., et al., 2007. Projet Zemongo - Un aperçu du contexte écologique et de la pression anthropique sur les resources naturelles de la Réserve de Faune de Zemongo, Préfecture du Haut-Mbomou, République Centrafricaine.

Ruggiero, R.G., 1991. Prey selection of the lion (Panthera leoL.)in the Manovo-Gounda-St. Floris National Park, Central AfricanRepublic. Mammalia 55, 23-33.

Stark, M.A., 1986. Daily movement, grazing activity and diet of savanna buffalo, Syncerus caffer brachyceros, in Benoue National Park, Cameroon. Afr. J. Ecol. 24 (4), 255-262. Stephens, P.A., et al., 2006. Estimating population density from indirect sign: track count and the Formozov-Malyshev-Pereleshin formula. Anim. Conserv. 9 (3), 339-348.

Stratford, K.J., Stratford, S.M., 2011. Fine-scale movements and use of space by spotted hyaena (Crocuta Crocuta) on Ongava Game Reserve, Namibia. Afr. J. Ecol. 49 (3), 343-352.

Thomas, L., et al., 2010. Distance software: design and analysis of distance sampling surveys for estimating population size. J. Appl. Ecol. 47, 5-14.

Van Orsdol, K.G., 1984. Foraging behaviour and hunting success of lions in Queen Elizabeth National Park, Uganda. Afr. J. Ecol. 22 (2), 79-99.

Webster, H., McNutt, J., McComb, 2010. Eavesdropping and risk assessment between lions, spotted hyenas and African wild dogs. Ethology 116 (3), 233-239.

Wilson, D., Mittermeier, R., 2009. Mammals of the World Vol. 1 Carnivores. Lynx Editions.

Woodroffe, R., Ginsberg, J.R., 1998. Edge effects and the extinction of populations inside protected areas. Science 280 (5372), 2126-2128.

Woodroffe, R., Sillero-Zubiri, C., 2012. Lycaon pictus. The IUCN Red List of Threatened Species 2012: e.T12436A16711116. https://doi.org/10.2305/IUCN.UK.2012.RLTS. T12436A16711116.en. Downloaded on 26 September 2017.

Zecchini, M., Mattiello, S., 2016. The Right of Sahelian Transhumant People. Problems and Progress in Land, Water and Resources Rights at the Beginning of the third Millennium. pp. 181-192. 